\title{
Membrane Trafficking Illuminates a Path to Parkinson's Disease
}

\author{
Takafumi Hasegawa, ${ }^{1}$ Naoto Sugeno, ${ }^{1}$ Akio Kikuchi, ${ }^{1}$ Toru Baba ${ }^{2}$ and \\ Masashi Aoki ${ }^{1}$
${ }^{1}$ Division of Neurology, Department of Neuroscience and Sensory Organs, Tohoku University Graduate School of Medicine, Sendai, Miyagi, Japan
${ }^{2}$ Department of Behavioral Neurology and Cognitive Neuroscience, Tohoku University Graduate School of \\ Medicine, Sendai, Miyagi, Japan
}

\begin{abstract}
Parkinson's disease (PD) is the second most common neurodegenerative disorder that is characterized by progressive movement disability and a variety of non-motor symptoms. The neuropathology of PD consists of the loss of dopaminergic neurons in the midbrain and the appearance of neuronal inclusions called Lewy bodies, which contain insoluble $\alpha$-synuclein, a relatively small protein originally identified in association with synaptic vesicles in the presynaptic nerve terminals. Drugs that replenish dopamine can partly alleviate the motor symptoms, but they do not cure the disease itself. Therefore, there is an urgent need for disease modification in terms of the delay or prevention of neurodegeneration. Recent advances in genetic and biochemical studies have provided unifying conceptual frameworks of the pathogenesis of PD. Particularly, membrane trafficking has aroused special attention as an initiator or enhancer of the neurodegenerative process that leads to PD. Defects in the cellular trafficking pathway result in synaptic dysfunction and the accumulation of misfolded $\alpha$-synuclein. Likewise, changes in intracellular sorting and degradation profoundly influence the cellular trafficking of misfolded proteins, thereby facilitating the cell-to-cell spreading of hazardous $\alpha$-synuclein species in a prion-like manner. Here, we will review our current knowledge of the functional roles of membrane trafficking in PD and will discuss how this cellular process could induce or facilitate the functional and pathological alterations in this disease.
\end{abstract}

Keywords: $\alpha$-synuclein; Lewy body; membrane trafficking; Parkinson's disease; prion-like propagation Tohoku J. Exp. Med., 2017 May, 242 (1), 63-76. (C) 2017 Tohoku University Medical Press

\section{Introduction}

In 1817, James Parkinson, an English physician and paleontologist, first described six cases of what he called the "shaking palsy" (paralysis agitans) (Parkinson 1817). Later, a French neurologist, Jean-Martin Charcot, named the condition Parkinson's disease (PD) in recognition of the importance of Parkinson's work (Jost and Reichmann 2017). Clinically, PD is characterized by a chronic, progressive increase in movement disability, impaired balance, and a variety of nonmotor symptoms (Takeda et al. 2010, 2014; Kikuchi et al. 2011, 2013; Baba et al. 2012, 2017; Odagiri et al. 2016). The neuropathological hallmark of PD is the preferential loss of pigmented dopaminergic neurons in the substantia nigra pars compacta and the appearance of intracellular inclusions named Lewy bodies (LBs), which are primarily composed of hyperphosphorylated, filamentous $\alpha$-synuclein $(\alpha \mathrm{SYN})$ aggregates (Spillantini et al. 1997). According to the Braak's pathological staging of
PD, a six-stage system based on the presence of LB pathology is suggested to indicate a hierarchical progression from medullary and olfactory nuclei to the neocortex (Braak et al. 2003). In stage 1, the LBs are confined to the olfactory bulb and the dorsal motor nucleus of the vagus nerve. In stage 2, Lewy bodies continue to ascend into the brainstem, reaching the medulla oblongata and pontine tegmentum, parts of the brainstem that control swallowing, sleep, and other autonomic functions affected in PD. By Stage 3 and 4, LBs start to appear in the amygdala (almond-shaped groups of nuclei involved in processing emotions and odor discrimination) and in the dopaminergic neurons in the substantia nigra; this is the stage when typical motor symptoms are expected to arise. In stages 5 and 6, LB pathology distributes throughout the entire neocortex, at which point dementia manifests itself clinically. Although the motor symptoms of PD can be improved using dopamine replacement medications, there is still a need to develop diseasemodifying therapies that are able to delay or prevent the ill-

Received April 7, 2017; revised and accepted May 8, 2017. Published online May 25, 2017; doi: 10.1620/tjem.242.63.

Correspondence: Takafumi Hasegawa, M.D., Ph.D., Division of Neurology, Department of Neuroscience and Sensory Organs, Tohoku

University Graduate School of Medicine, 1-1 Seiryo-machi, Aoba-ku, Sendai, Miyagi 980-8574, Japan.

e-mail: thasegawa@med.tohoku.ac.jp

Dr. Takafumi Hasegawa is a recipient of the 2016 Gold Prize, Tohoku University School of Medicine. 
ness. The presence of $\alpha \mathrm{SYN}$-positive intracellular inclusions in PD and its related disorders provides a conceptual link that has led to the use of "synucleinopathy" as umbrella term that encompasses these diseases (Wakabayashi et al. 2007). Although the native conformation of $\alpha \mathrm{SYN}$ in the human brain is still a topic of debate (Bartels et al. 2011), the central region of $\alpha \mathrm{SYN}$ (residues 61-95) constitutes the hydrophobic core of the protein, also known as the non-amyloid- $\beta$ component of Alzheimer disease (NAC) domain, and this structural region allows $\alpha \mathrm{SYN}$ to achieve a $\beta$-sheet-rich conformation that facilitates selfaggregation (Ueda et al. 1994; Weinreb et al. 1996; Hasegawa et al. 2004; Matsuzaki et al. 2004). Mounting evidence supports the general hypothesis that the accumulation of misfolded, aggregated proteins in the nervous tissues not only represents pathological hallmarks but also triggers a complex series of noxious events that result in neuronal degeneration (Golde and Miller 2009; Kikuchi et al. 2010, 2016).

In addition to the delineation of the clinicopathological features of PD, substantial progress has been made between the late 20 th to the early 21 th centuries in understanding the biochemical processes and genetic factors of PD. For example, the discovery that exposure to several neurotoxins such as 1-methyl-4-phenyl-1,2,3,6-tetrahydropyridine (MPTP) (Langston et al. 1983), manganese (Florence and Stauber 1988), and pesticides, such as rotenone and paraquat (Tanner et al. 2011), causes parkinsonism with nigral cell death in humans and other vertebrates implicates the environmental etiology for PD. On the other hand, increasing evidence has suggested that a genetic factor has a strong impact on the pathogenesis of PD. Indeed, in the past two decades, more than 20 genes have been identified as causal and/or risk genes for PD (Ferreira and Massano 2017). In particular, the implication of $\alpha \mathrm{SYN}$ as a culprit of PD-linked neuropathology expanded enormously when the $S N C A$ gene (PARK1), which encodes $\alpha \mathrm{SYN}$, was identified as the first PD-related gene (Polymeropoulos et al. 1997). In this context, genetic and environmental factors may both be complexly interwoven in the pathophysiology of PD (Fig. 1). Although the cellular process underlying the selective neuronal loss in $\mathrm{PD}$ remains elusive, evidence from biochemical, toxicological, cellular, and genetic studies has provided several hypothetical pathogenetic cascades,

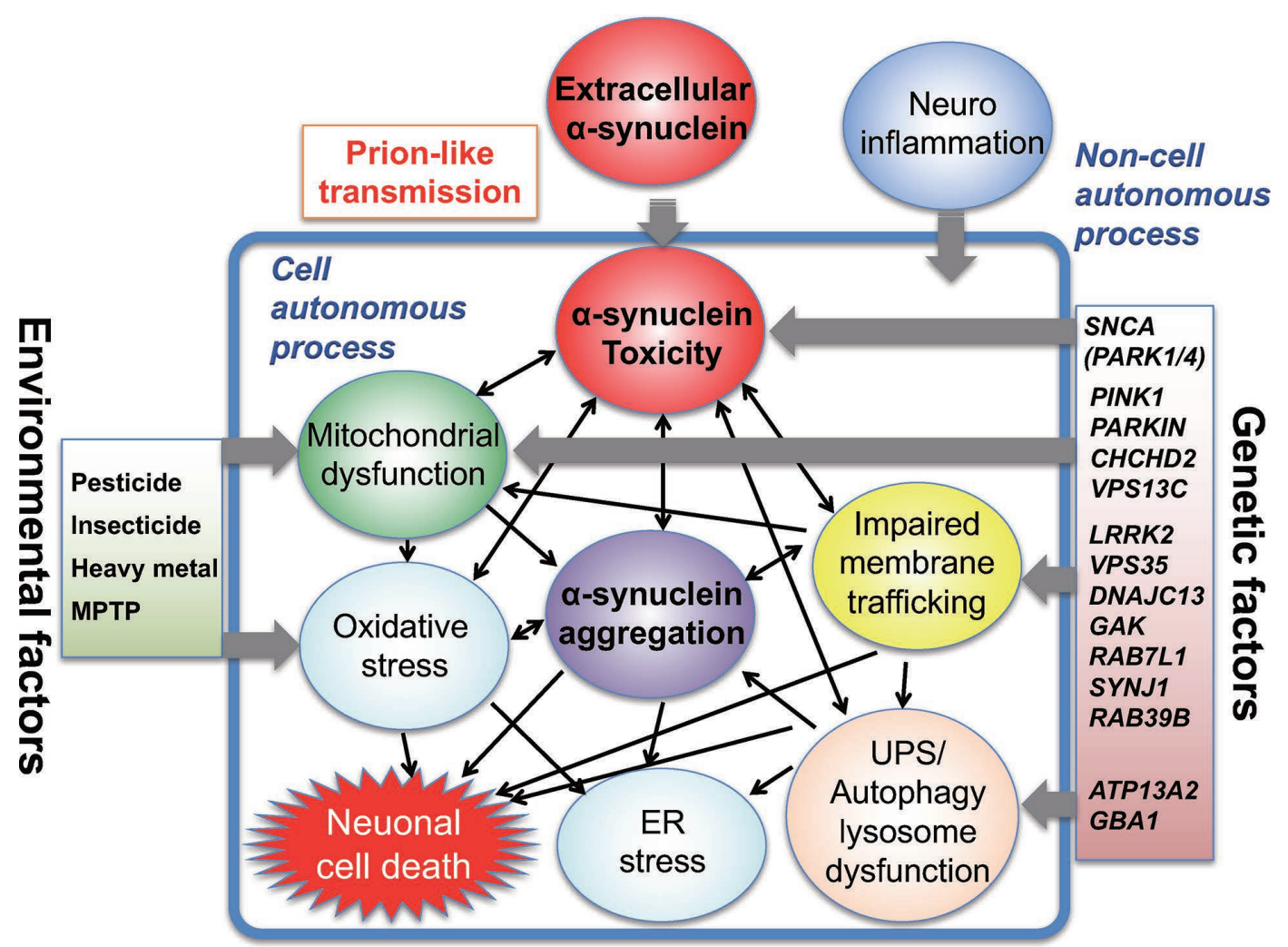

Fig. 1. Schematic presentation of neuronal death in Parkinson's disease.

In sporadic Parkinson's disease (PD), the interplay between genetic predisposition and environmental risk factors is believed to initiate the pathological cascade. On the other hand, in the case of familial PD, distinct genes/proteins mainly contribute to the initiation and amplification of pathological processes. As the main component of Lewy bodies, $\alpha$-synuclein is the product of the first gene (SNCA) identified as being associated with the familial forms of PD. Under pathological conditions, $\alpha$-synuclein aggregates to form insoluble fibrils, triggering a complex series of cytotoxic events that result in dopaminergic neuronal degeneration, indicating that $\alpha$-synuclein plays a central role in the pathogenesis of PD. In addition, non-cell autonomous processes such as the prion-like transmission of $\alpha$-synuclein and neuroinflammation, supposedly influence neurodegeneration. 
including oxidative stress (Hasegawa et al. 2003, 2006, 2007; Hasegawa 2010), endoplasmic reticulum stress (Sugeno et al. 2008; Mercado et al. 2016), mitochondrial dysfunction (Mizuno et al. 1998; Rothfuss et al. 2009), misfolded protein toxicity (Hasegawa et al. 2004; Furukawa et al. 2006; Takeda et al. 2006), ubiquitin-proteasome dysfunction (Hasegawa et al. 2008; Vilchez et al. 2014; Matsuda 2016), neuroinflammation (Takeda et al. 2006), impairment of the autophagy-lysosome system (Ferrucci et al. 2008; Oshima et al. 2016), and alterations in the membrane trafficking pathway (Abeliovich and Gitler 2016). Among them, recent advances in clinical genetics and studies using model organisms have emphasized that the membrane trafficking pathway contributes immensely to the pathogenesis of PD and related neurodegenerative disorders.

In this review, we will describe the details of how the membrane trafficking contributes to neuronal maintenance, as well as the degenerative process in PD. Specifically, we will first focus on the biophysical role of $\alpha \mathrm{SYN}$ as an effector for membrane trafficking such as synaptic vesicle transport. Next, we will provide several examples of the types of genetic defects in the elements of membrane trafficking that could contribute to the pathogenesis of PD. Finally, we will argue the importance of the membrane trafficking machinery as a proof-of-concept for the "prion-like" phenomenon in synucleinopathy.

\section{Membrane trafficking -a specialized cellular logistics}

Membrane trafficking is a type of cellular logistics by which proteins and other large molecules in transport vesicles are able to reach their appropriate destinations without crossing a membrane (Cheung and de Vries 2008). Hence, it is not surprising that membrane trafficking plays crucial roles in not only in maintaining cellular homeostasis but also in fulfilling specific demands during development, differentiation, signal perception and transduction (Hasegawa et al. 2000, 2001; Rodriguez et al. 2001; Da Silva et al. 2005; Wang et al. 2013). Transport vesicles are constantly formed at the plasma membrane, endoplasmic reticulum (ER), and Golgi apparatus. In this process, cargo-containing vesicles arise at a donor compartment with the cooperation of specific coat and adaptor proteins, and they are targeted along their cytoskeletal components to the acceptor sites, to which they fuse with the help of soluble NSF (N-ethylmaleimide-sensitive factor)-attachment protein receptor (SNARE) complex (Wickner and Rizo 2017). In eukaryotic cells, membrane vesicular trafficking is roughly divided into two major routes, namely, exocytosis and endocytosis (Fig. 2). In the exocytosis pathway, newly synthesized proteins are translocated into the ER. From the ER, membranous vesicles deliver the cargo to the Golgi apparatus. The ER-derived cargo enters the cis-Golgi com-

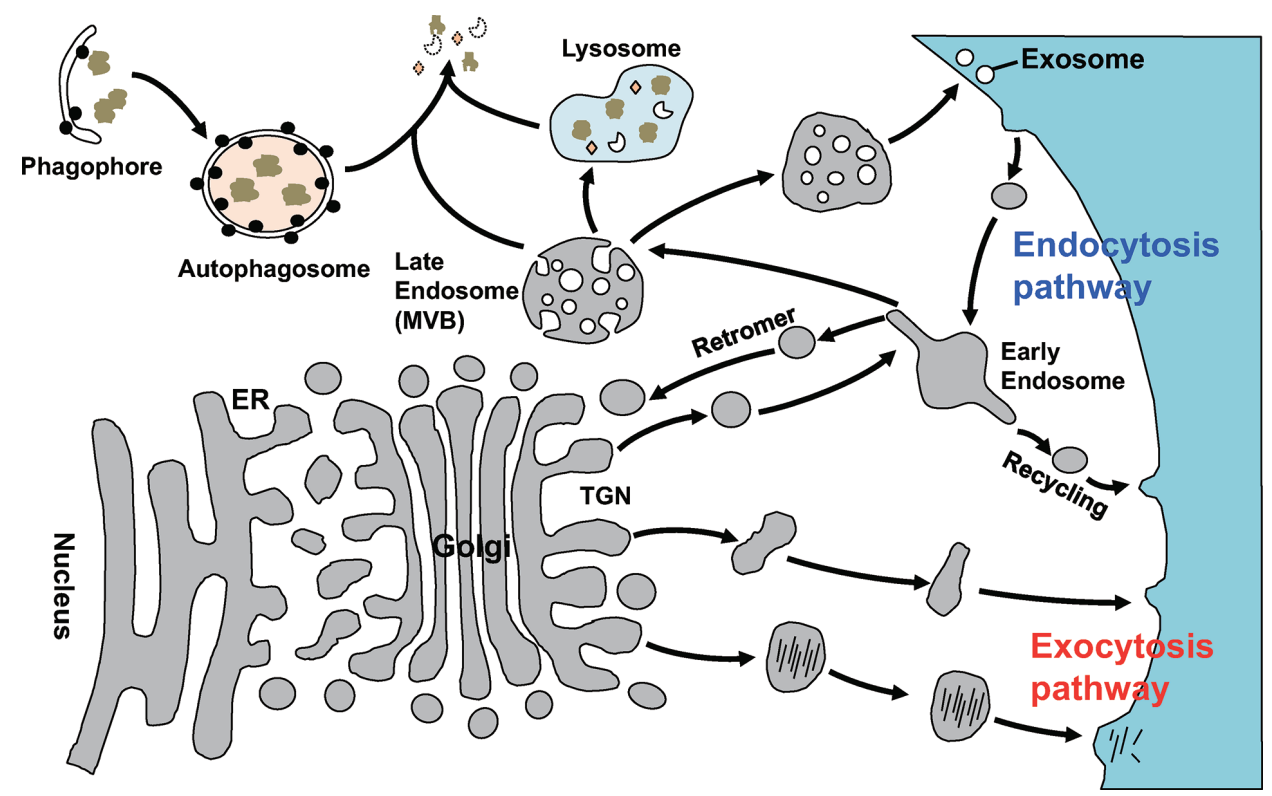

Fig. 2. The dynamics of membrane trafficking in eukaryotic cells.

In eukaryotic cells, membrane vesicular trafficking is divided into two major routes. In the exocytosis pathway, newly synthesized proteins are translocated into the ER. ER-derived cargo enters the cis-Golgi complex and moves through the TGN. On the other hand, endocytosis is a gateway into cells by which proteins are internalized from the cell surface to the early endosome. The early endosome determines the subsequent fate of the internalized cargo, destining it either to the plasma membrane for recycling, to the lysosomes for degradation or to the TGN for retrieval. The transition from early to late endosome is associated with an increased number of intraluminal vesicles (MVBs). MVBs and lysosomes cooperatively participate in autophagic proteolysis. An alternative destination of MVBs is their exocytic fusion with the plasma membrane, which leads to the release of intraluminal vesicles (also known as exosomes) into the extracellular milieu. 
plex and moves through the medial and trans-Golgi network (TGN). One could even say that the Golgi apparatus is the major sorting hub because, in the Golgi, cargo is sorted not only to the plasma membrane for secretion but also to the endosomes and lysosomes, or it can be recycled back to the ER (Makowski et al. 2017). On the other hand, endocytosis is a gateway into the cells, by which proteins and membrane are internalized from the cell surface to the early endosome. The early endosome serves as the primary sorting station and also determines the fate of the internalized cargo (Jovic et al. 2010). Namely, upon reaching this compartment, the cargo takes charge of its own destiny and plays an active role in its own trafficking by recruiting specific regulators, such as the small Rab GTPases (Pfeffer 2017). These sorting events determine the subsequent fate of the internalized cargo, destining it to the plasma membrane for recycling, to the lysosomes for degradation or to the TGN for retrieval. The transition from early to late endosome is associated with an increased number of intraluminal vesicles (multivesicular bodies, MVBs), luminal acidification and endosomal movement from the cell periphery towards a juxtanuclear location (Huotari and Helenius 2011). The MVB and lysosome cooperatively participate in autophagic proteolysis, where they fuse with the autophagosome/autolysosome for the final execution of proteolytic degradation. An alternative destination of MVBs is their exocytic fusion with the inner leaflet of the plasma membrane, leading to the release of intraluminal vesicles (ILVs), also known as exosomes, into the extracellular milieu (Soria et al. 2017). The sorting of cargoes into ILVs from MVBs is a tightly regulated process that depends on a highly conserved functional complex called the endosomal sorting complex required for transport (ESCRT) (Hurley and Hanson 2010). Both ubiquitin ligases and deubiquitinating enzymes play a regulatory role in this process, as specific ubiquitin-tagging determines the destination of cargo proteins or the stability of ESCRT components (Raiborg and Stenmark 2009; Oshima et al. 2016).

\section{$\alpha$-synuclein as a regulator of membrane trafficking}

The first $\alpha \mathrm{SYN}$ was identified in 1988 from the electric organ of Torpedo californica as a protein that localized to the presynaptic nerve terminals and nuclei of neurons (Maroteaux et al. 1988; Schell et al. 2009; Sugeno et al. 2016). Human $\alpha \mathrm{SYN}$ is a relatively small protein, consisting of 140 amino acids, and has a predicted molecular mass of $14 \mathrm{kDa} . \alpha \mathrm{SYN}$ is primarily found in neuronal protein, making up as much as $1 \%$ of all the proteins in the neuronal cytosol, but it is also detected in non-neuronal cells, such as red blood cells (Nakai et al. 2007). Although the exact physiological function(s) of $\alpha \mathrm{SYN}$ remains uncertain, its localization at pre-synaptic nerve terminals and its preferential interaction with membrane phospholipids imply that this protein may associate with synaptic transmission and lipid vesicle trafficking (Perrin et al. 2000; Outeiro and Lindquist 2003). Indeed, $\alpha \mathrm{SYN}$ binds to the phospholipid membrane, allowing the initiation of membrane curvature formation (Westphal and Chandra 2013). Mice lacking $\alpha \mathrm{SYN}$ are viable, exhibiting minor neurological deficits that are accompanied by alterations in the level of dopamine and the turnover of phospholipids in the brain (Abeliovich et al. 2000; Drolet et al. 2004). Electrophysiological examination revealed that $\alpha \mathrm{SYN}$-ablated mice exhibited an impaired synaptic response to a prolonged train of repetitive stimulation, possibly due to the delayed replenishment of the docked vesicles by the reserve pool vesicles after depletion (Cabin et al. 2002). In addition, cell biological studies demonstrated that $\alpha \mathrm{SYN}$ has a physical interaction with presynaptic SNARE proteins, and there is a linear relationship between the $\alpha \mathrm{SYN}$ level and SNARE complex formation, suggesting that $\alpha \mathrm{SYN}$ may influence SNARE assembly at the presynaptic terminal (Burre et al. 2010). Further evidence of this putative function of $\alpha \mathrm{SYN}$ was strengthened by the discovery that $\alpha \mathrm{SYN}$ might be able to fine-tune the ability of arachidonic acid to regulate SNARE complex formation (Darios et al. 2010). Intriguingly, an endogenous level of $\alpha \mathrm{SYN}$ was protective against the neurodegeneration caused by the depletion of SNARE chaperone cysteinestring protein $\alpha(\operatorname{CSP} \alpha)$, while its over-expression in a transgenic mouse model resulted in the disassembly of SNARE proteins (Chandra et al. 2005; Sudhof and Rizo 2011). Despite the fact that SNAP-25 can be co-immunoprecipitated with $\alpha \mathrm{SYN}$ (Burre et al. 2010) and there is a direct interaction between VAMP2 and the $\mathrm{C}$ terminus of $\alpha \mathrm{SYN}$ (Burre et al. 2012), $\alpha \mathrm{SYN}$ transgenic mice exhibit only a mild neurological phenotype (Rockenstein et al. 2002). Supposedly, $\alpha$ SYN does not seem to be a key determinant of neurosecretion and synaptic activities, but it may exert a buffering action for presynaptic function.

Another line of evidence from the studies using yeast and mammalian cells highlighted the functional interrelationship between $\alpha \mathrm{SYN}$ and Rab protein, a master regulator of membrane trafficking (Pfeffer 2017). While SNARE proteins are exclusively involved in membrane fusion events, the Rab GTPase has much more diverse functions. Like other GTPases, Rab GTPases switch between two conformations, a GTP-bound active form and a GDP-bound inactive form, thereby shuttling between the specific membrane compartment and the cytosol (Muller and Goody 2017). As the molecular switch, Rab GTPases offer significant roles in the formation, budding, fusion, transport and docking of the vesicle. The over-expression of $\alpha \mathrm{SYN}$ in a yeast model resulted in dose-dependent toxicity, which was accompanied by the accumulation of vacuoles and aggregated $\alpha$ SYN with multiple Rab GTPases (Soper et al. 2011). $\alpha \mathrm{SYN}$ interacts with prenylated Rab acceptor protein (PRA1), found in the Golgi and late endosomes, and regulates the cycling of Rab GTPases during exocytosis and endocytosis (Lee et al. 2011). Furthermore, in primary neurons, $\alpha \mathrm{SYN}$ fibrils triggered the buildup of endogenous $\alpha \mathrm{SYN}$ in axons and disrupted the Rab7-positive endosomal transport and fusion step with lysosome (Volpicelli-Daley 
et al. 2014). Notably, co-immunoprecipitation studies using brain samples of dementia with Lewy bodies (DLB) and multiple system atrophy (MSA) and transgenic mouse demonstrated a physical interaction between $\alpha \mathrm{SYN}$ and Rab3a, Rab5, and Rab8 (Dalfo et al. 2004a, b; Dalfo and Ferrer 2005). From the observation in yeast and nematode models, overexpressed $\alpha \mathrm{SYN}$ seems to interfere with a variety of trafficking steps, e.g., ER-Golgi trafficking, endocytosis, exocytosis, and retromer-mediated retrograde transport between the endosome to the Golgi apparatus (Chua and Tang 2011; Goncalves and Outeiro 2016), suggesting that pathologically accumulated $\alpha \mathrm{SYN}$ may be related to Golgi and endosomal trafficking.

\section{Membrane trafficking defect in Parkinson's disease}

Although more than $90 \%$ of PD cases are sporadic, the identification of several genes linked to the rare familial forms of PD has offered great insight into the biochemical and molecular mechanisms of the disease. Of note, recent advance in molecular genetics have underscored the relevance of endo-lysosome trafficking machinery in the pathogenesis of PD (Fig. 3). The discovery of missense mutations in the genes of VPS35 (PARK17), which encodes a vital element of the retromer complex, has implicated retromer dysfunction in PD pathogenesis (Vilarino-Guell et al. 2011; Zimprich et al. 2011). The retromer complex mediates the retrograde transport of cargo from the endosome to the TGN (Seaman 2004). Structurally, the retromer is comprised of two distinct subcomplexes: a cargo-recognition VPS26-VPS29-VPS35 heterotrimer and a membrane-targeting dimer of the sorting nexin (SNX1 and/or SNX2). Cell biological studies have shown that the PD-linked
D620N VPS35 mutant associates poorly with the WASH (Wiskott-Aldrich syndrome protein and SCAR homolog) complex and impairs WASH recruitment to the endosomes (McGough et al. 2014). Interestingly, autophagy is impaired in cells expressing the PD-mutant VPS35 or lacking WASH, which could be explained, at least in part, by the abnormal trafficking of ATG9A, a transmembrane protein that is required for autophagosome biogenesis (Zavodszky et al. 2014). Several groups, including us, have noted that VPS35-retromer dysfunction has also been directly coupled to $\alpha \mathrm{SYN}$-related cytotoxicity. Retromer malfunction increases the lysosomal turnover of the mannose 6-phosphate receptor, thereby affecting the trafficking of cathepsin D (CTSD), a major lysosomal aspartyl protease that is involved in $\alpha \mathrm{SYN}$ degradation (Follett et al. 2014; Miura et al. 2014). We found that the genetic ablation of Drosophila Vps35 not only induced the accumulation of the detergent-insoluble $\alpha \mathrm{SYN}$ species in the central nervous system but also exacerbated both locomotor impairments and compound eye degeneration in human $\alpha \mathrm{SYN}$-transgenic flies (Miura et al. 2014). Intriguingly, MacLeod et al. (2013) have demonstrated that wild-type (wt) VPS35 could rescue the phenotypes caused by $L R R K 2$ (leucine-rich repeat kinase 2) (PARK8) or RAB7L1 (PARK16) risk variants both in vitro and in vivo, suggesting that these PD-associated genes might configure a common cellular pathway. Although the exact function of LRRK2 remains to be elucidated, a role for LRRK2 in vesicular dynamics came from subcellular localization studies, which showed the localization of LRRK2 with endosomes, lysosomes and MVBs in the rodent brain and with the punctate, vesicular structures in human brain (Roosen and Cookson

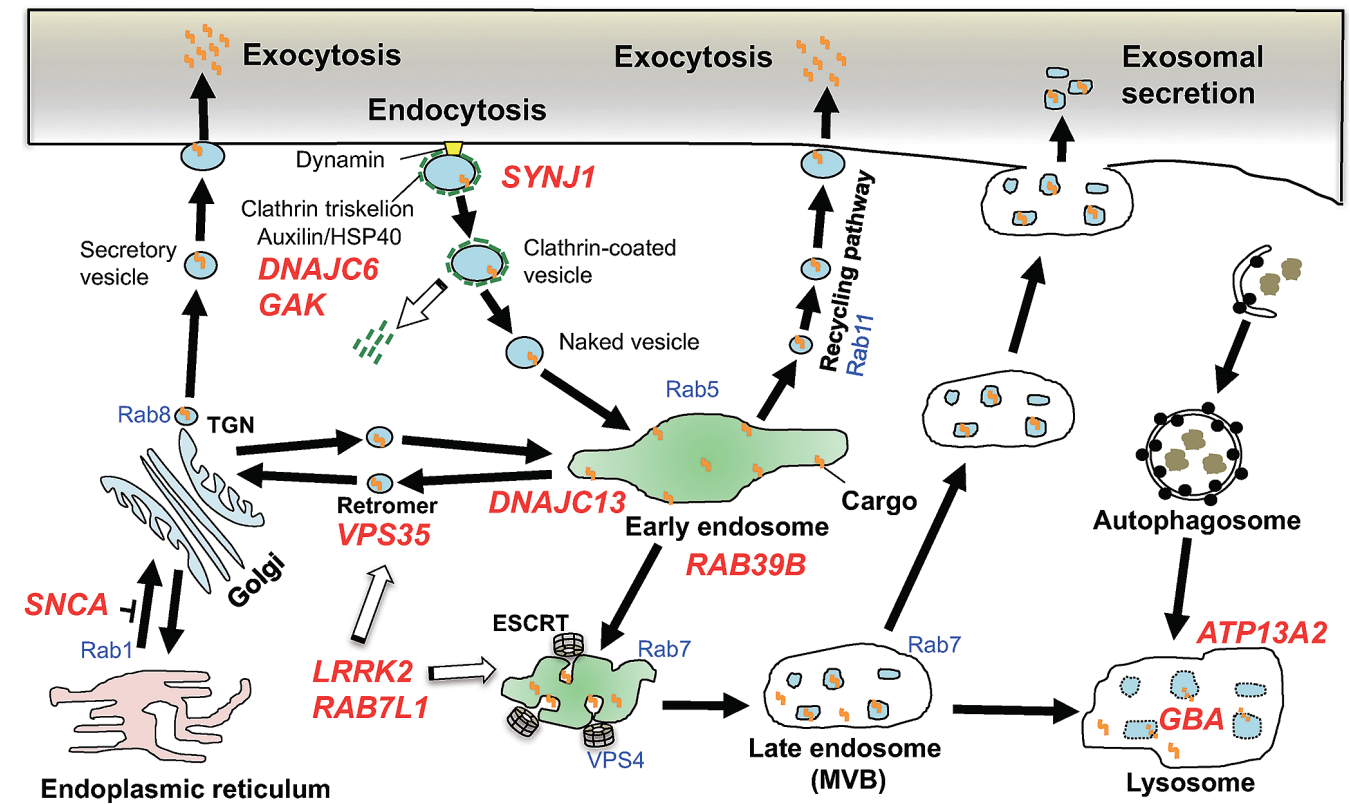

Fig. 3. Membrane trafficking defect in Parkinson's disease.

Recent advances in molecular genetics have underscored the relevance of the endo-lysosome trafficking machinery in the pathogenesis of PD. Highlighted in red is the PD-linked gene encoding proteins in the endo-lysosomal pathway. Rab protein, a master regulator of membrane trafficking, is indicated in blue. 
2016). Further studies using cellular and animal models have suggested that the mutant forms of LRRK2 decrease LC3 lipidation and result in the accumulation of autophagic vacuoles (Roosen and Cookson 2016). In addition, LRRK2 was shown to interact with a number of Rab GTPases, including Rab7, Rab32 and Rab38 (Waschbusch et al. 2014).

Recently, three functionally related genes (DNAJC13, $D N A J C 6$, and $G A K$ ) encoding proteins in the evolutionarily conserved Dnaj/Hsp40 protein family have been identified as the PD-related genes (Cardona and Perez-Tur 2016). DNAJC13 (Dnaj (Hsp40) homolog, subfamily C, member 13) is a responsible gene that is responsible for the autosomal-dominant PARK21-linked familial form of PD (Vilarino-Guell et al. 2014). DNAJC13 was originally identified as the mammalian homolog of receptor mediated endocytosis $8(R M E-8)$ in a screen for the endocytic defect phenotype in Caenorhabditis elegans (Zhang et al. 2001). As the name implies, several lines of evidence indicate that RME-8 may serve as the regulator of endocytosis. Nevertheless, subsequent studies have suggested that this phenotype per se is attributed to its involvement in the postendocytic trafficking machinery (Freeman et al. 2014). More specifically, RME-8 is supposed to play a crucial role in the recycling and the degradation of the EGF receptor and transferrin (Fujibayashi et al. 2008), as well as the retrograde retrieval of CI-MPR (Girard et al. 2005). Importantly, both VPS35 and RME-8 have been shown to interact with the WASH complex, raising the possibility that theses two proteins could merge into a common molecular path in terms of the endosomal trafficking pathway (Seaman and Freeman 2014). DNAJC6 mutations were recently described in two families with autosomal recessive juvenile atypical parkinsonism (PARK19) (Edvardson et al. 2012). DNAJC6 encodes the neuron-specific isoform of auxilin. Auxilins have a crucial role in clathrin-mediated endocytosis (CME). In neurons, CME plays a key role in the formation of new vesicles at the presynaptic terminal and the recycling of synaptic vesicles. Intriguingly, common variants in cyclin-G-associated kinase (GAK), which encodes auxilin-2, a ubiquitously expressed form of auxilin, have also been identified by genome-wide association studies as a risk factor for late-onset idiopathic PD (Pankratz et al. 2009), further supporting disturbed synaptic vesicle endocytosis and trafficking in the pathogenesis of PD. The gene SYNJ1 encodes synaptojanin-1, a presynaptically enriched protein that is involved in synaptic vesicle exocytosis (Harris et al. 2000). Mutations in SYNJ1 may provoke defects in endo-lysosomal trafficking at the presynaptic nerve terminal, thereby causing atypical parkinsonism with epileptic seizure (PARK20) (Krebs et al. 2013). Most recently, $R A B 39 B$ has been reported as a novel causative gene for X-linked intellectual disability and early-onset PD with $\alpha$ SYN-pathology (Wilson et al. 2014). Rab39B protein is also a member of the Rab-family GTPases that localizes in the early endosome.
Although they does not seem to be the bona fide components of the membrane trafficking machinery, mutations in several genes encoding lysosome-associated proteins are also known to be the causes of and/or risks for PD (AharonPeretz et al. 2004). In particular, mutations of the genes encoding a lysosomal acid $\beta$-glucocerebrosidase (GCase) are the most important risk factor yet discovered for PD (Schapira 2015). Heterozygous mutations in GBA1, which encodes GCase, increase the risk of PD 5-fold, and approximately $5-10 \%$ of sporadic PD patients carry GBAl gene mutations. Glucocerebrosidase can affect $\alpha \mathrm{SYN}$ proteostasis through various mechanisms; however, an interesting scenario is that the accumulation of substrates such as glycosylceramide due to GBA loss-of-function may also facilitate $\alpha \mathrm{SYN}$ oligomerization. On the other hand, $\alpha \mathrm{SYN}$ oligomers in the lysosome may impact on GBA, leading to its malfunction and creating a vicious cycle of lysosomal failure and pathological $\alpha \mathrm{SYN}$ accumulation (Mazzulli et al. 2011). Another piece of evidence showed that mutations in the ATP13A2 gene, which encodes a lysosomal ATPase cation transporter and causes autosomal recessive familial PD (PARK9, also known as Kufor-Rakeb syndrome), enhances $\alpha \mathrm{SYN}$ aggregation and affects its exosomal secretion into the extracellular space (Tsunemi et al. 2014; Lopes da Fonseca et al. 2016). Taken together, these genetic discoveries strongly support the notion that the defects in endo-lysosomal trafficking/functions are illuminated as convergent mechanisms for PD and related neurological disorders.

\section{Membrane trafficking and the cell-to-cell spreading phenomenon}

Prion-like propagation as a pathogenic principle for synucleinopathy

It has long been considered that $\alpha \mathrm{SYN}$ solely exerts its physiological and pathogenic effects intracellularly. However, increasing evidence suggests that both monomeric and oligomeric $\alpha \mathrm{SYN}$ secreted into the extracellular environment can transfer from cell-to-cell, thereby affecting the normal physiological state of the neighboring cells in a prion-like manner (Lee et al. 2010b). $\alpha \mathrm{SYN}$ has been found in the neuronal culture medium, as well as in body fluids, such as plasma and cerebrospinal fluid (CSF) (Hasegawa et al. 2011). The existence of extracellular $\alpha \mathrm{SYN}$ is also supported by the fact that the hydrophobic core region of $\alpha \mathrm{SYN}$, termed NAC, is observed in the extracellular senile plaques of Alzheimer's disease (AD) (Ueda et al. 1994). The exact biochemical influence of extracellular $\alpha \mathrm{SYN}$ is not yet understood, but soluble $\alpha \mathrm{SYN}$ oligomers can induce the transmembrane seeding of $\alpha \mathrm{SYN}$ aggregation and can eventually cause cell death (Lee 2008). The intercellular transmission of $\alpha \mathrm{SYN}$ has also been verified by co-culture experiments and in vivo animal models showing that $\alpha \mathrm{SYN}$ aggregates released from neuronal cells can be transferred to neighboring cells and can form intracellular inclusions (Desplats et al. 2009; Lee et al. 2010a; 
Konno et al. 2012; Masuda-Suzukake et al. 2013). Moreover, it has been shown that $\alpha \mathrm{SYN}$-containing conditioned medium not only induced neuronal death but also triggered inflammatory responses in astroglial cells (Lee et al. 2010a). Finally, the in vivo cell-to-cell transmission of pathogenic protein was strongly supported by postmortem pathology showing that $\alpha \mathrm{SYN}$-positive, LB-like inclusions were found in the fetal mesencephalic neurons that were transplanted into the brain of PD patients more than a decade previously (Kordower et al. 2008; Li et al. 2008). Conceptually, this scenario is attractive as a feasible explanation for the clinically observed progression of neurodegenerative diseases, as well as the topographic spread of LB pathology suggested by Braak and his colleagues (Braak et al. 2003). In addition to PD, the intercellular transmission of $\alpha$ SYN pathology can be assumed to be present in MSA, in which widespread $\alpha \mathrm{SYN}$-positive glial cytoplasmic inclusions (GCIs) are found in oligodendroglia, a type of brain cell that does not seem to express $\alpha \mathrm{SYN}$ under physiological conditions (Hasegawa et al. 2010; Kikuchi et al. 2010; Hasegawa 2013; Prusiner et al. 2015). Furthermore, several other aggregation-prone, "prionoid" proteins such as $\beta$-amyloid, tau, polyglutamine (polyQ) and TAR DNAbinding protein 43 (TDP-43), share some aspects of prions, although none of these has been shown to be transmissible in nature or in experimental animals (Walker and Jucker 2015). Under such situations, there is an urgent need to elucidate the cellular mechanisms by which each prionoid protein can enter and leave neuronal and glial cells.

\section{How does exogenous $\alpha$-synuclein get into cells?}

The internalization of $\alpha \mathrm{SYN}$ into cells is supposedly initiated by its attachment to the outer surface of the plasma membrane via its amphipathic N-terminal domain (Ahn et al. 2006), which facilitates membrane curvature, tubulation and breaking. While several reports claimed that part of extracellular $\alpha \mathrm{SYN}$ could be transferred from cell-to-cell via an extracellular nanovesicle, called exosome (Emmanouilidou et al. 2010), accumulating evidence suggests that endocytosis plays a fundamental role in $\alpha \mathrm{SYN}$ internalization both in neuronal and glial cells (Lee et al. 2008; Desplats et al. 2009; Konno et al. 2012) (Fig. 4). Intriguingly, an early endosome marker, Rab5A is critical for the endocytosis of exogenous $\alpha \mathrm{SYN}$ into neuronal cells (Sung et al. 2001). In a yeast model, the A30P mutant $\alpha$ SYN was shown to bind the endocytic cargo-transport protein YPP1 at the plasma membrane, which led to the budding of endocytic vesicles via receptor-mediated endocytosis and the subsequent targeting of this form of $\alpha \mathrm{SYN}$ to the vacuole for degradation (Flower et al. 2007). The

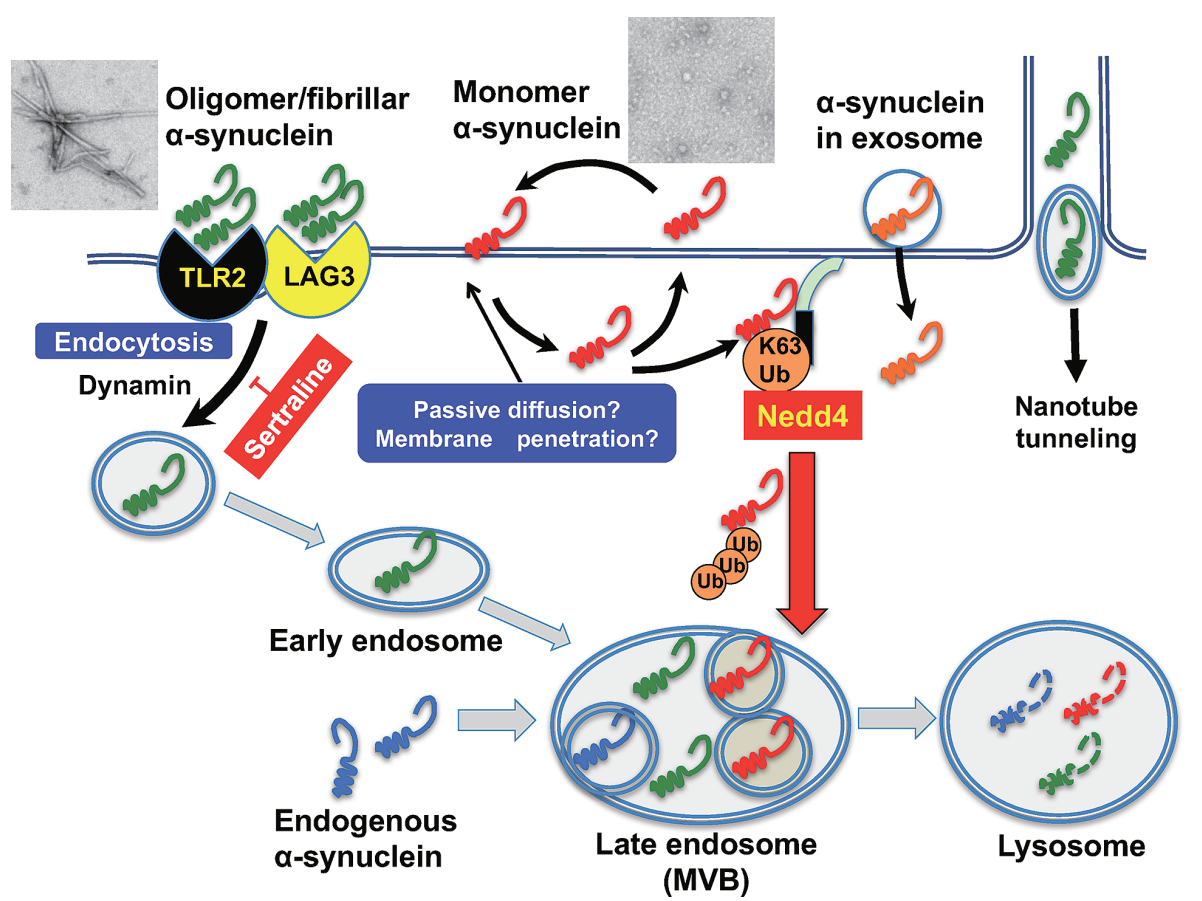

Fig. 4. The internalization mechanisms of extracellular $\alpha$-synuclein.

The endocytic process plays a key role in the oligomeric and the fibrillar forms of $\alpha \mathrm{SYN}$ internalization, both in neuronal and in glial cells. The TLR2 and LAG3 expressed on neurons and/or glial cells may serve as a putative receptor for extracellular $\alpha \mathrm{SYN}$ fibrils, leading to their endocytosis. On the other hand, $\alpha \mathrm{SYN}$ monomer directly passes through the plasma membrane, possibly through direct membrane penetration, the formation of annular, pore-like structures, or tunneling-nanotubes between the cells. The Nedd4 E3 ligase catalyzes the K63-linked polyubiquitination of the internalized $\alpha \mathrm{SYN}$ monomer, thereby facilitating its targeting to late endosomes. Similar to prion protein, part of $\alpha \mathrm{SYN}$ could be transferred from cell-to-cell via an extracellular nanovesicle, called exosome, and/or tunneling nanotubes. The upper left and upper middle insets are the transmission electron microscope images of fibrillar and monomeric $\alpha \mathrm{SYN}$, respectively. 
importance of the endocytic process in the uptake of extracellular $\alpha \mathrm{SYN}$ is further supported by our findings, which show that genetic as well as pharmacological disruption of the dynamin GTPases through the administration of sertraline, a widely used selective serotonin reuptake inhibitor (SSRI) antidepressant, significantly decreased the internalization and translocation of $\alpha \mathrm{SYN}$ in neuronal and oligodendroglial cells (Konno et al. 2012). In fact, neuropsychiatric manifestations such as depression, anhedonia, and anxiety are frequently encountered as non-motor symptoms in PD (Stefanova et al. 2000). SSRIs are widely used as a first-line therapy for PD-associated depression. Thus, the identification of novel therapeutic aspects of sertraline not only provides a strategy focused on the prevention of the cell-to-cell transmission of $\alpha \mathrm{SYN}$ but also has the advantage of utilizing time-tested drugs for the benefit of the patients. Despite the substantial role of endocytosis in the uptake process of $\alpha \mathrm{SYN}, \alpha \mathrm{SYN}$ internalization was not completely blocked by the disruption of the endocytic machinery (Konno et al. 2012), indicating the existence of alternative mechanisms other than endocytosis. Indeed, there is evidence showing that fibrillar and non-fibrillar $\alpha \mathrm{SYN}$ species were incorporated via the endocytic machinery, while an $\alpha \mathrm{SYN}$ monomer directly passed through the plasma membrane (Lee et al. 2008; Sugeno et al. 2014). Unfortunately, it remains to be determined how $\alpha \mathrm{SYN}$ crosses the cellular membrane; however, several possibilities have been postulated such as direct penetration (Ahn et al. 2006), formation of annular, pore-like structures (Volles and Lansbury 2002), tunneling-nanotubes (Abounit et al. 2016; Dieriks et al. 2017), or macropinocytosis (Lee et al. 2010b). Regardless of the mechanisms involved in $\alpha \mathrm{SYN}$ internalization, it seems likely that parts of the extrinsic $\alpha \mathrm{SYN}$ species can directly enter neuronal and/or glial cells where they get access to the cytosolic compartment and are subjected to further processing, modification, and transport. We found that Nedd4 E3 ligase catalyzes the K63-linked poly-ubiquitination of monomeric $\alpha \mathrm{SYN}$, thereby facilitating its targeting to late endosomes (Sugeno et al. 2014). Considering the possible target(s) of the pharmacological inhibition of $\alpha \mathrm{SYN}$ internalization, a fundamental question is whether $\alpha \mathrm{SYN}$ endocytosis relies on a specific receptor or not. In this regard, toll-like receptor 2 (TLR2) in neuron and microglial cells could serve as the receptor for extracellular $\alpha$ SYN oligomers (Kim et al. 2013). Furthermore, a recent study has identified the lymphocyte-activation gene 3 (LAG3), also known as CD223, as the binding partner for preformed $\alpha \mathrm{SYN}$ fibrils (Mao et al. 2016). The LAG3 expressed on neurons may serve as a putative receptor for extracellular $\alpha \mathrm{SYN}$ fibrils, leading to their endocytosis. These findings provide a useful hint for developing diseasehalting therapies of PD and other synucleinopathies.

\section{The secretory mechanism-similarities and differences between prion and $\alpha$-synuclein}

In the case of prion protein, cell-to-cell transmission by means of an exosome shuttle (Fevrier et al. 2004), caveolae-mediated endosomal pathway (Peters et al. 2003), and tunneling nanotubes (Gousset et al. 2009) have been suggested. In this regard, it is tempting to speculate that similar mechanisms could be involved in the transmission of other amyloidogenic proteins including $\alpha \mathrm{SYN}$. Given that prion enrichment and infectivity were confirmed in the culture media of infected cells and body fluids from suffering animals, prion transfer seems to occur by a process other than direct cell contact (Porto-Carreiro et al. 2005; Vella et al. 2008). In addition to prion protein, several reports have suggested that the exosome may serve as an extracellular vehicle for the spread of amyloidogenic protein in other neurodegenerative diseases including PD (Aguzzi and Rajendran 2009; Frost and Diamond 2010; Lee et al. 2010b). We found a striking condensation of prion in the exosomes of culture medium and human CSF, whereas such enrichment was not observed with $\alpha \mathrm{SYN}$ (Hasegawa et al. 2011). The marked discrepancy in terms of the exosomal localization implies that the secretory mechanism of $\alpha \mathrm{SYN}$ might be different from that of prion protein. This idea is also supported by our findings, which show that, in contrast to prion protein, the suppression of MVB-exosome biogenesis by the dominant-negative mutant VPS4A dramatically increased extracellular $\alpha \mathrm{SYN}$ in non-neuronal and neuronal cells (Hasegawa et al. 2011). It is true that our results would seem to conflict with previous reports demonstrating that $\alpha \mathrm{SYN}$ is secreted from neuronal cells by exosomes (Emmanouilidou et al. 2010; Alvarez-Erviti et al. 2011). However, it remains possible that $\alpha \mathrm{SYN}$ might be secreted through different secretory pathways depending on the size of the aggregates or the cellular conditions. Indeed, prior studies have suggested that $\alpha \mathrm{SYN}$ secretion may rely on unconventional, ER/Golgi-independent exocytosis (Lee et al. 2005) or Rab27A-mediated autophagosome-mediated exocytosis (also known as "exophagy") (Ejlerskov et al. 2013). Furthermore, several groups, including us, demonstrated that the internalized extracellular $\alpha \mathrm{SYN}$ was resecreted out of neurons via a process that is modulated by the slow recycling endosome regulator Rab11a (Liu et al. 2009; Hasegawa et al. 2011). Over-expression of the dominantnegative mutant Rab11a restored the aberrant $\alpha \mathrm{SYN}$ secretion that was triggered by impaired MVB genesis also supports the functional relevance of the recycling pathway in $\alpha$ SYN secretion (Hasegawa et al. 2011). Accordingly, under physiological conditions, endosomal $\alpha \mathrm{SYN}$ is destined for lysosomal degradation or guided into the extracellular milieu through the Rab11a-dependent slow recycling pathway and, to a lesser degree, MVB-exosomes and/or the exophagy pathway (Fig. 5). However, if the intracellular $\alpha \mathrm{SYN}$ reaches a toxic level or the MVB sorting pathway is dammed up for any reason, $\alpha \mathrm{SYN}$ may flow out, mainly through the recycling endosome pathway. Speculatively, the recycling pathway might serve as a "vent" to let potentially hazardous $\alpha \mathrm{SYN}$ out of the intracellular space. Intriguingly, we observed that the aggregation tendency of 


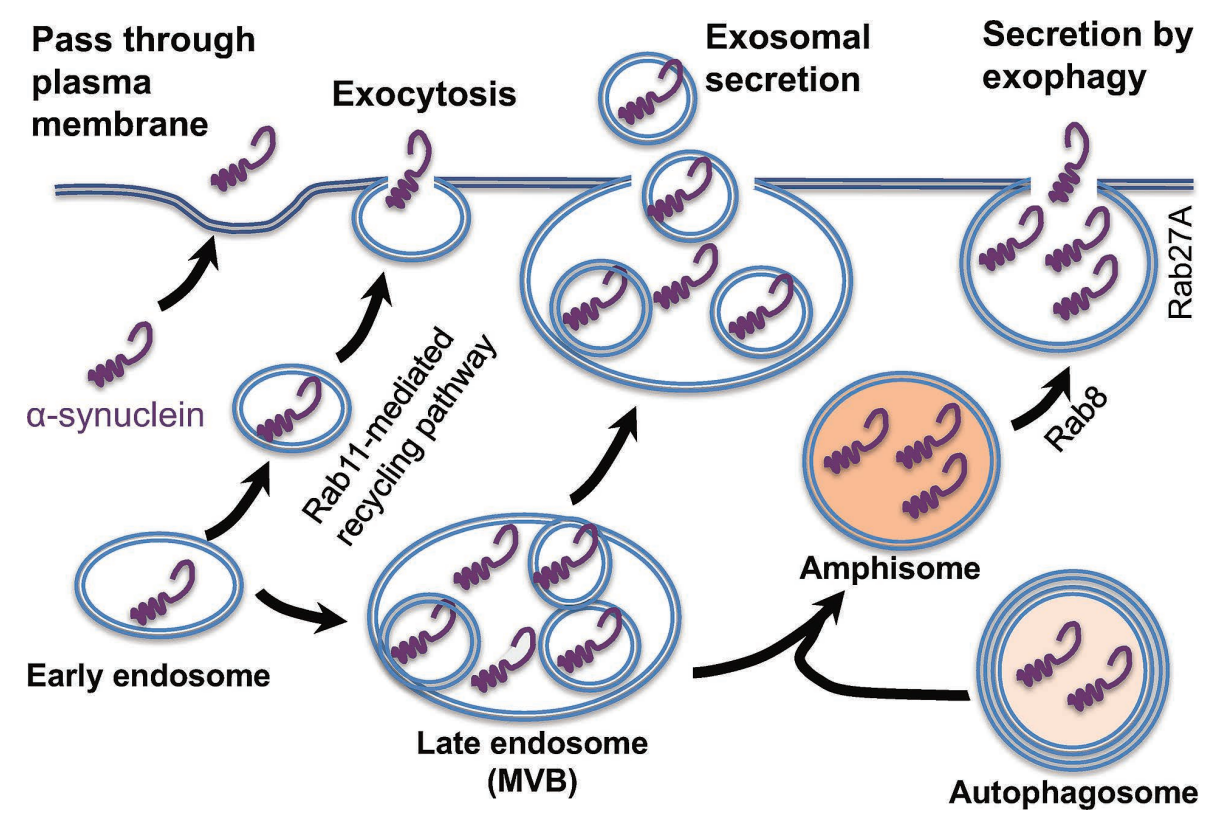

Fig. 5. The secretory pathway of $\alpha$-synuclein.

It is possible that part of cytosolic $\alpha \mathrm{SYN}$ could pass directly throuth the plasma membrane. On the other hand, endosomal $\alpha \mathrm{SYN}$ is guided into the extracellular space through the Rab11a-dependent slow recycling pathway and, to a lesser degree, MVB-exosome and/or an autophagosome-mediated secretory pathway termed exophagy.

$\alpha \mathrm{SYN}$ was prominent in the endocytic vesicles rather than in the cytosol (Hasegawa et al. 2011; Konno et al. 2012). This is interesting when considering the biogenesis of LBs, because the pale body, an early cytoplasmic change before Lewy body maturation, often contains ubiquitinated proteins in addition to lysosomes and vacuolar structures (Hayashida et al. 1993). It is uncertain why intravesicular $\alpha \mathrm{SYN}$ has a high propensity to form aggregates; however, unique environments inside the endo-lysosome, such as a high calcium concentration and a low $\mathrm{pH}$, might synergistically promote the conformational change of $\alpha \mathrm{SYN}$. In addition, we also found that endosome-resident $\alpha \mathrm{SYN}$ was robustly ubiquitinated compared with $\alpha \mathrm{SYN}$ in the cytosol (Hasegawa et al. 2011), suggesting a role for ubiquitin in $\alpha \mathrm{SYN}$ sorting along the endosomal pathway, as multiple monoubiquitylation and Lys-63-linked polyubiquitylation have been recognized as important sorting signals for cargo proteins in the endosomal membrane (Sugeno et al. 2014; Oshima et al. 2016).

\section{Concluding remarks}

In this review we have discussed the scientific progress made so far in the field of PD research. In particular, the wealth of genetic and biochemical studies strongly suggests that PD pathogenesis converges on the paradigm of the vesicle-mediated membrane trafficking pathway, which considerably affects diverse cellular events, including synaptic function and $\alpha \mathrm{SYN}$ degradation. Furthermore, intracellular trafficking strictly regulates the uptake and the secretion of $\alpha \mathrm{SYN}$, thereby influencing the transcellular spreading phenomenon. Deciphering the precise mode of intercellular sorting and degradation of $\alpha \mathrm{SYN}$ will shed light on the pathogenic mechanisms involved and will open up a new avenue for novel therapeutic interventions of PD and other related neurodegenerative diseases. Given the potential role of extracellular $\alpha \mathrm{SYN}$ aggregates as the real culprit of prion-like propagation, antibody-based therapy for the clearance of transmissible $\alpha \mathrm{SYN}$ species is currently on the way (Lee and Lee 2016). Alternatively, from a mechanistic point of view, it could be possible to prevent $\alpha \mathrm{SYN}$ entry into cells by blocking endocytic processes using a pharmacological inhibitor of dynamin (e.g., sertraline) or an anti-LAG3 antibody. Our earnest hope for disease-modifying therapy for this devastating disease may become a reality in the near future.

\section{Acknowledgments}

This work was supported in part by a Grant-in-Aid for Scientific Research (C) [grant number 17K09744] and a Grantin-Aid for Scientific Research on Innovative Areas (Brain Protein Aging and Dementia Control) [grant number 17H05683] from the Ministry of Education, Culture, Sports, Science and Technology (MEXT); a Grant-in-Aid for the Research Committee for Ataxic Diseases and a Grant-in-Aid for Practical Research Projects for Rare/Intractable Diseases and Translational Research Network Program (seed A) from the Japan Agency for Medical Research and Development (AMED).

\section{Conflict of Interest}

The authors declare no conflict of interest.

\section{References}

Abeliovich, A. \& Gitler, A.D. (2016) Defects in trafficking bridge Parkinson's disease pathology and genetics. Nature, 539, 207-216.

Abeliovich, A., Schmitz, Y., Farinas, I., Choi-Lundberg, D., Ho, 
W.H., Castillo, P.E., Shinsky, N., Verdugo, J.M., Armanini, M., Ryan, A., Hynes, M., Phillips, H., Sulzer, D. \& Rosenthal, A. (2000) Mice lacking alpha-synuclein display functional deficits in the nigrostriatal dopamine system. Neuron, 25, 239-252.

Abounit, S., Bousset, L., Loria, F., Zhu, S., de Chaumont, F., Pieri, L., Olivo-Marin, J.C., Melki, R. \& Zurzolo, C. (2016) Tunneling nanotubes spread fibrillar alpha-synuclein by intercellular trafficking of lysosomes. EMBO J., 35, 2120-2138.

Aguzzi, A. \& Rajendran, L. (2009) The transcellular spread of cytosolic amyloids, prions, and prionoids. Neuron, 64, 783-790.

Aharon-Peretz, J., Rosenbaum, H. \& Gershoni-Baruch, R. (2004) Mutations in the glucocerebrosidase gene and Parkinson's disease in Ashkenazi Jews. N. Engl. J. Med., 351, 1972-1977.

Ahn, K.J., Paik, S.R., Chung, K.C. \& Kim, J. (2006) Amino acid sequence motifs and mechanistic features of the membrane translocation of alpha-synuclein. J. Neurochem., 97, 265-279.

Alvarez-Erviti, L., Seow, Y., Schapira, A.H., Gardiner, C., Sargent, I.L., Wood, M.J. \& Cooper, J.M. (2011) Lysosomal dysfunction increases exosome-mediated alpha-synuclein release and transmission. Neurobiol. Dis., 42, 360-367.

Baba, T., Hosokai, Y., Nishio, Y., Kikuchi, A., Hirayama, K., Suzuki, K., Hasegawa, T., Aoki, M., Takeda, A. \& Mori, E. (2017) Longitudinal study of cognitive and cerebral metabolic changes in Parkinson's disease. J. Neurol. Sci., 372, 288-293.

Baba, T., Kikuchi, A., Hirayama, K., Nishio, Y., Hosokai, Y., Kanno, S., Hasegawa, T., Sugeno, N., Konno, M., Suzuki, K., Takahashi, S., Fukuda, H., Aoki, M., Itoyama, Y., Mori, E. \& Takeda, A. (2012) Severe olfactory dysfunction is a prodromal symptom of dementia associated with Parkinson's disease: a 3 year longitudinal study. Brain, 135, 161-169.

Bartels, T., Choi, J.G. \& Selkoe, D.J. (2011) alpha-Synuclein occurs physiologically as a helically folded tetramer that resists aggregation. Nature, 477, 107-110.

Braak, H., Del Tredici, K., Rub, U., de Vos, R.A., Jansen Steur, E.N. \& Braak, E. (2003) Staging of brain pathology related to sporadic Parkinson's disease. Neurobiol. Aging, 24, 197-211.

Burre, J., Sharma, M. \& Sudhof, T.C. (2012) Systematic mutagenesis of alpha-synuclein reveals distinct sequence requirements for physiological and pathological activities. J. Neurosci., 32, 15227-15242.

Burre, J., Sharma, M., Tsetsenis, T., Buchman, V., Etherton, M.R. \& Sudhof, T.C. (2010) Alpha-synuclein promotes SNAREcomplex assembly in vivo and in vitro. Science, 329, 16631667.

Cabin, D.E., Shimazu, K., Murphy, D., Cole, N.B., Gottschalk, W., McIlwain, K.L., Orrison, B., Chen, A., Ellis, C.E., Paylor, R., Lu, B. \& Nussbaum, R.L. (2002) Synaptic vesicle depletion correlates with attenuated synaptic responses to prolonged repetitive stimulation in mice lacking alpha-synuclein. $J$. Neurosci., 22, 8797-8807.

Cardona, F. \& Perez-Tur, J. (2016) Other proteins involved in Parkinson's disease and related disorders. Curr. Protein Pept. Sci., [Epub ahead of print].

Chandra, S., Gallardo, G., Fernandez-Chacon, R., Schluter, O.M. \& Sudhof, T.C. (2005) Alpha-synuclein cooperates with CSPalpha in preventing neurodegeneration. Cell, 123, 383-396.

Cheung, A.Y. \& de Vries, S.C. (2008) Membrane trafficking: intracellular highways and country roads. Plant Physiol., 147, 1451-1453.

Chua, C.E. \& Tang, B.L. (2011) Rabs, SNAREs and alpha-synuclein-membrane trafficking defects in synucleinopathies. Brain Res. Rev., 67, 268-281.

Da Silva, J.S., Hasegawa, T., Miyagi, T., Dotti, C.G. \& AbadRodriguez, J. (2005) Asymmetric membrane ganglioside sialidase activity specifies axonal fate. Nat. Neurosci., 8, 606-615.
Dalfo, E., Albasanz, J.L., Martin, M. \& Ferrer, I. (2004a) Abnormal metabotropic glutamate receptor expression and signaling in the cerebral cortex in diffuse Lewy body disease is associated with irregular alpha-synuclein/phospholipase C (PLCbeta1) interactions. Brain Pathol., 14, 388-398.

Dalfo, E., Barrachina, M., Rosa, J.L., Ambrosio, S. \& Ferrer, I. (2004b) Abnormal alpha-synuclein interactions with rab3a and rabphilin in diffuse Lewy body disease. Neurobiol. Dis., 16, 92-97.

Dalfo, E. \& Ferrer, I. (2005) Alpha-synuclein binding to rab3a in multiple system atrophy. Neurosci. Lett., 380, 170-175.

Darios, F., Ruiperez, V., Lopez, I., Villanueva, J., Gutierrez, L.M. \& Davletov, B. (2010) Alpha-synuclein sequesters arachidonic acid to modulate SNARE-mediated exocytosis. EMBO Rep., 11, 528-533.

Desplats, P., Lee, H.J., Bae, E.J., Patrick, C., Rockenstein, E., Crews, L., Spencer, B., Masliah, E. \& Lee, S.J. (2009) Inclusion formation and neuronal cell death through neuron-toneuron transmission of alpha-synuclein. Proc. Natl. Acad. Sci. USA, 106, 13010-13015.

Dieriks, B.V., Park, T.I., Fourie, C., Faull, R.L., Dragunow, M. \& Curtis, M.A. (2017) alpha-synuclein transfer through tunneling nanotubes occurs in SH-SY5Y cells and primary brain pericytes from Parkinson's disease patients. Sci. Rep., 7, 42984.

Drolet, R.E., Behrouz, B., Lookingland, K.J. \& Goudreau, J.L. (2004) Mice lacking alpha-synuclein have an attenuated loss of striatal dopamine following prolonged chronic MPTP administration. Neurotoxicology, 25, 761-769.

Edvardson, S., Cinnamon, Y., Ta-Shma, A., Shaag, A., Yim, Y.I., Zenvirt, S., Jalas, C., Lesage, S., Brice, A., Taraboulos, A., Kaestner, K.H., Greene, L.E. \& Elpeleg, O. (2012) A deleterious mutation in DNAJC6 encoding the neuronal-specific clathrin-uncoating co-chaperone auxilin, is associated with juvenile parkinsonism. PLoS One, 7, e36458.

Ejlerskov, P., Rasmussen, I., Nielsen, T.T., Bergstrom, A.L., Tohyama, Y., Jensen, P.H. \& Vilhardt, F. (2013) Tubulin polymerization-promoting protein (TPPP/p25alpha) promotes unconventional secretion of alpha-synuclein through exophagy by impairing autophagosome-lysosome fusion. J. Biol. Chem., 288, 17313-17335.

Emmanouilidou, E., Melachroinou, K., Roumeliotis, T., Garbis, S.D., Ntzouni, M., Margaritis, L.H., Stefanis, L. \& Vekrellis, K. (2010) Cell-produced alpha-synuclein is secreted in a calcium-dependent manner by exosomes and impacts neuronal survival. J. Neurosci., 30, 6838-6851.

Ferreira, M. \& Massano, J. (2017) An updated review of Parkinson's disease genetics and clinicopathological correlations. Acta Neurol. Scand., 135, 273-284.

Ferrucci, M., Pasquali, L., Ruggieri, S., Paparelli, A. \& Fornai, F. (2008) Alpha-synuclein and autophagy as common steps in neurodegeneration. Parkinsonism Relat. Disord., 14 Supple 2, S180-S184.

Fevrier, B., Vilette, D., Archer, F., Loew, D., Faigle, W., Vidal, M., Laude, H. \& Raposo, G. (2004) Cells release prions in association with exosomes. Proc. Natl. Acad. Sci. USA, 101, 96839688.

Florence, T.M. \& Stauber, J.L. (1988) Neurotoxicity of manganese. Lancet, $\mathbf{1}, 363$.

Flower, T.R., Clark-Dixon, C., Metoyer, C., Yang, H., Shi, R., Zhang, Z. \& Witt, S.N. (2007) YGR198w (YPP1) targets A30P alpha-synuclein to the vacuole for degradation. J. Cell Biol., 177, 1091-1104.

Follett, J., Norwood, S.J., Hamilton, N.A., Mohan, M., Kovtun, O., Tay, S., Zhe, Y., Wood, S.A., Mellick, G.D., Silburn, P.A., Collins, B.M., Bugarcic, A. \& Teasdale, R.D. (2014) The Vps35 D620N Mutation Linked to Parkinson's Disease Disrupts the Cargo Sorting Function of Retromer. Traffic, 15, 230-244.

Freeman, C.L., Hesketh, G. \& Seaman, M.N. (2014) RME-8 coor- 
dinates the activity of the WASH complex with the function of the retromer SNX dimer to control endosomal tubulation. $J$. Cell Sci., 127, 2053-2070.

Frost, B. \& Diamond, M.I. (2010) Prion-like mechanisms in neurodegenerative diseases. Nat. Rev. Neurosci., 11, 155-159.

Fujibayashi, A., Taguchi, T., Misaki, R., Ohtani, M., Dohmae, N., Takio, K., Yamada, M., Gu, J., Yamakami, M., Fukuda, M., Waguri, S., Uchiyama, Y., Yoshimori, T. \& Sekiguchi, K. (2008) Human RME-8 is involved in membrane trafficking through early endosomes. Cell Struct. Funct., 33, 35-50.

Furukawa, K., Matsuzaki-Kobayashi, M., Hasegawa, T., Kikuchi, A., Sugeno, N., Itoyama, Y., Wang, Y., Yao, P.J., Bushlin, I. \& Takeda, A. (2006) Plasma membrane ion permeability induced by mutant alpha-synuclein contributes to the degeneration of neural cells. J. Neurochem., 97, 1071-1077.

Girard, M., Poupon, V., Blondeau, F. \& McPherson, P.S. (2005) The DnaJ-domain protein RME-8 functions in endosomal trafficking. J. Biol. Chem., 280, 40135-40143.

Golde, T.E. \& Miller, V.M. (2009) Proteinopathy-induced neuronal senescence: a hypothesis for brain failure in Alzheimer's and other neurodegenerative diseases. Alzheimers Res. Ther., 1, 5.

Goncalves, S.A. \& Outeiro, T.F. (2016) Traffic jams and the complex role of alpha-Synuclein aggregation in Parkinson disease. Small GTPases, 1-7, doi: 10.1080/21541248.2016.1 199191. [Epub ahead of print].

Gousset, K., Schiff, E., Langevin, C., Marijanovic, Z., Caputo, A., Browman, D.T., Chenouard, N., de Chaumont, F., Martino, A., Enninga, J., Olivo-Marin, J.C., Mannel, D. \& Zurzolo, C. (2009) Prions hijack tunnelling nanotubes for intercellular spread. Nat. Cell Biol., 11, 328-336.

Harris, T.W., Hartwieg, E., Horvitz, H.R. \& Jorgensen, E.M. (2000) Mutations in synaptojanin disrupt synaptic vesicle recycling. J. Cell Biol., 150, 589-600.

Hasegawa, T. (2010) Tyrosinase-expressing neuronal cell line as in vitro model of Parkinson's disease. Int. J. Mol. Sci., 11, 1082-1089.

Hasegawa, T., Baba, T., Kobayashi, M., Konno, M., Sugeno, N., Kikuchi, A., Itoyama, Y. \& Takeda, A. (2010) Role of TPPP/ p25 on alpha-synuclein-mediated oligodendroglial degeneration and the protective effect of SIRT2 inhibition in a cellular model of multiple system atrophy. Neurochem. Int., 57, 857-866.

Hasegawa, T., Feijoo Carnero, C., Wada, T., Itoyama, Y. \& Miyagi, T. (2001) Differential expression of three sialidase genes in rat development. Biochem. Biophys. Res. Commun., 280, 726-732.

Hasegawa, T., Kikuchi, A. \& Takeda, A. (2013) Pathogenesis of multiple system atrophy. Neurol. Clin. Neurosci., 1, 189-194.

Hasegawa, T., Konno, M., Baba, T., Sugeno, N., Kikuchi, A., Kobayashi, M., Miura, E., Tanaka, N., Tamai, K., Furukawa, K., Arai, H., Mori, F., Wakabayashi, K., Aoki, M., Itoyama, Y. \& Takeda, A. (2011) The AAA-ATPase VPS4 regulates extracellular secretion and lysosomal targeting of alpha-synuclein. PLoS One, 6, e29460.

Hasegawa, T., Matsuzaki, M., Takeda, A., Kikuchi, A., Akita, H., Perry, G., Smith, M.A. \& Itoyama, Y. (2004) Accelerated alpha-synuclein aggregation after differentiation of SH-SY5Y neuroblastoma cells. Brain Res., 1013, 51-59.

Hasegawa, T., Matsuzaki, M., Takeda, A., Kikuchi, A., Furukawa, K., Shibahara, S. \& Itoyama, Y. (2003) Increased dopamine and its metabolites in SH-SY5Y neuroblastoma cells that express tyrosinase. J. Neurochem., 87, 470-475.

Hasegawa, T., Matsuzaki-Kobayashi, M., Takeda, A., Sugeno, N., Kikuchi, A., Furukawa, K., Perry, G., Smith, M.A. \& Itoyama, Y. (2006) Alpha-synuclein facilitates the toxicity of oxidized catechol metabolites: implications for selective neurodegeneration in Parkinson's disease. FEBS Lett., 580, 2147-2152.

Hasegawa, T., Sugeno, N., Takeda, A., Matsuzaki-Kobayashi, M., Kikuchi, A., Furukawa, K., Miyagi, T. \& Itoyama, Y. (2007)
Role of Neu4L sialidase and its substrate ganglioside GD3 in neuronal apoptosis induced by catechol metabolites. FEBS Lett., 581, 406-412.

Hasegawa, T., Treis, A., Patenge, N., Fiesel, F.C., Springer, W. \& Kahle, P.J. (2008) Parkin protects against tyrosinase-mediated dopamine neurotoxicity by suppressing stress-activated protein kinase pathways. J. Neurochem., 105, 1700-1715.

Hasegawa, T., Yamaguchi, K., Wada, T., Takeda, A., Itoyama, Y. \& Miyagi, T. (2000) Molecular cloning of mouse ganglioside sialidase and its increased expression in Neuro2a cell differentiation. J. Biol. Chem., 275, 8007-8015.

Hayashida, K., Oyanagi, S., Mizutani, Y. \& Yokochi, M. (1993) An early cytoplasmic change before Lewy body maturation: an ultrastructural study of the substantia nigra from an autopsy case of juvenile parkinsonism. Acta Neuropathol., 85, 445-448.

Huotari, J. \& Helenius, A. (2011) Endosome maturation. EMBO $J ., 30,3481-3500$.

Hurley, J.H. \& Hanson, P.I. (2010) Membrane budding and scission by the ESCRT machinery: it's all in the neck. Nat. Rev. Mol. Cell Biol., 11, 556-566.

Jost, W.H. \& Reichmann, H. (2017) "An essay on the shaking palsy" 200 years old. J. Neural. Transm., doi:10.1007/s00702017-1684-0. [Epub ahead of print].

Jovic, M., Sharma, M., Rahajeng, J. \& Caplan, S. (2010) The early endosome: a busy sorting station for proteins at the crossroads. Histol. Histopathol., 25, 99-112.

Kikuchi, A., Baba, T., Hasegawa, T., Kobayashi, M., Sugeno, N., Konno, M., Miura, E., Hosokai, Y., Ishioka, T., Nishio, Y., Hirayama, K., Suzuki, K., Aoki, M., Takahashi, S., Fukuda, H., Itoyama, Y., Mori, E. \& Takeda, A. (2013) Hypometabolism in the supplementary and anterior cingulate cortices is related to dysphagia in Parkinson's disease: a cross-sectional and 3-year longitudinal cohort study. BMJ Open, 3, e002249.

Kikuchi, A., Baba, T., Hasegawa, T., Sugeno, N., Konno, M. \& Takeda, A. (2011) Differentiating Parkinson's disease from multiple system atrophy by [123I] meta-iodobenzylguanidine myocardial scintigraphy and olfactory test. Parkinsonism Relat. Disord., 17, 698-700.

Kikuchi, A., Okamura, N., Hasegawa, T., Harada, R., Watanuki, S., Funaki, Y., Hiraoka, K., Baba, T., Sugeno, N., Oshima, R., Yoshida, S., Kobayashi, J., Ezura, M., Kobayashi, M., Tano, O., et al. (2016) In vivo visualization of tau deposits in corticobasal syndrome by 18 F-THK5351 PET. Neurology, 87, 2309-2316.

Kikuchi, A., Takeda, A., Okamura, N., Tashiro, M., Hasegawa, T., Furumoto, S., Kobayashi, M., Sugeno, N., Baba, T., Miki, Y., Mori, F., Wakabayashi, K., Funaki, Y., Iwata, R., Takahashi, S., Fukuda, H., Arai, H., Kudo, Y., Yanai, K. \& Itoyama, Y. (2010) In vivo visualization of alpha-synuclein deposition by carbon11-labelled 2-[2-(2-dimethylaminothiazol-5-yl)ethenyl]-6-[2(fluoro)ethoxy]benzoxazole positron emission tomography in multiple system atrophy. Brain, 133, 1772-1778.

Kim, C., Ho, D.H., Suk, J.E., You, S., Michael, S., Kang, J., Joong Lee, S., Masliah, E., Hwang, D., Lee, H.J. \& Lee, S.J. (2013) Neuron-released oligomeric alpha-synuclein is an endogenous agonist of TLR2 for paracrine activation of microglia. Nat. Commun., 4, 1562.

Konno, M., Hasegawa, T., Baba, T., Miura, E., Sugeno, N., Kikuchi, A., Fiesel, F.C., Sasaki, T., Aoki, M., Itoyama, Y. \& Takeda, A. (2012) Suppression of dynamin GTPase decreases alpha-synuclein uptake by neuronal and oligodendroglial cells: a potent therapeutic target for synucleinopathy. Mol. Neurodegener., 7, 38.

Kordower, J.H., Chu, Y., Hauser, R.A., Freeman, T.B. \& Olanow, C.W. (2008) Lewy body-like pathology in long-term embryonic nigral transplants in Parkinson's disease. Nat. Med., 14, 504-506.

Krebs, C.E., Karkheiran, S., Powell, J.C., Cao, M., Makarov, V., 
Darvish, H., Di Paolo, G., Walker, R.H., Shahidi, G.A., Buxbaum, J.D., De Camilli, P., Yue, Z. \& Paisan-Ruiz, C. (2013) The Sac1 domain of SYNJ1 identified mutated in a family with early-onset progressive Parkinsonism with generalized seizures. Hum. Mutat., 34, 1200-1207.

Langston, J.W., Ballard, P., Tetrud, J.W. \& Irwin, I. (1983) Chronic Parkinsonism in humans due to a product of meperidineanalog synthesis. Science, 219, 979-980.

Lee, H.J., Kang, S.J., Lee, K. \& Im, H. (2011) Human alpha-synuclein modulates vesicle trafficking through its interaction with prenylated Rab acceptor protein 1. Biochem. Biophys. Res. Commun., 412, 526-531.

Lee, H.J., Patel, S. \& Lee, S.J. (2005) Intravesicular localization and exocytosis of alpha-synuclein and its aggregates. $J$. Neurosci., 25, 6016-6024.

Lee, H.J., Suk, J.E., Bae, E.J., Lee, J.H., Paik, S.R. \& Lee, S.J. (2008) Assembly-dependent endocytosis and clearance of extracellular alpha-synuclein. Int. J. Biochem. Cell Biol., 40, 1835-1849.

Lee, H.J., Suk, J.E., Patrick, C., Bae, E.J., Cho, J.H., Rho, S., Hwang, D., Masliah, E. \& Lee, S.J. (2010a) Direct transfer of alpha-synuclein from neuron to astroglia causes inflammatory responses in synucleinopathies. J. Biol. Chem., 285, 92629272.

Lee, J.S. \& Lee, S.J. (2016) Mechanism of Anti-alpha-Synuclein Immunotherapy. J. Mov. Disord., 9, 14-19.

Lee, S.J. (2008) Origins and effects of extracellular alpha-synuclein: implications in Parkinson's disease. J. Mol. Neurosci., 34, 17-22.

Lee, S.J., Desplats, P., Sigurdson, C., Tsigelny, I. \& Masliah, E. (2010b) Cell-to-cell transmission of non-prion protein aggregates. Nat. Rev. Neurol., 6, 702-706.

Li, J.Y., Englund, E., Holton, J.L., Soulet, D., Hagell, P., Lees, A.J., Lashley, T., Quinn, N.P., Rehncrona, S., Bjorklund, A., Widner, H., Revesz, T., Lindvall, O. \& Brundin, P. (2008) Lewy bodies in grafted neurons in subjects with Parkinson's disease suggest host-to-graft disease propagation. Nat. Med., 14, 501-503.

Liu, J., Zhang, J.P., Shi, M., Quinn, T., Bradner, J., Beyer, R., Chen, S. \& Zhang, J. (2009) Rab11a and HSP90 regulate recycling of extracellular alpha-synuclein. J. Neurosci., 29, 14801485.

Lopes da Fonseca, T., Pinho, R. \& Outeiro, T.F. (2016) A familial ATP13A2 mutation enhances alpha-synuclein aggregation and promotes cell death. Hum. Mol. Genet., 25, 2959-2971.

MacLeod, D.A., Rhinn, H., Kuwahara, T., Zolin, A., Di Paolo, G., McCabe, B.D., Marder, K.S., Honig, L.S., Clark, L.N., Small, S.A. \& Abeliovich, A. (2013) RAB7L1 interacts with LRRK2 to modify intraneuronal protein sorting and Parkinson's disease risk. Neuron, 77, 425-439.

Makowski, S.L., Tran, T.T. \& Field, S.J. (2017) Emerging themes of regulation at the Golgi. Curr. Opin. Cell Biol., 45, 17-23.

Mao, X., Ou, M.T., Karuppagounder, S.S., Kam, T.I., Yin, X., Xiong, Y., Ge, P., Umanah, G.E., Brahmachari, S., Shin, J.H., Kang, H.C., Zhang, J., Xu, J., Chen, R., Park, H., et al. (2016) Pathological alpha-synuclein transmission initiated by binding lymphocyte-activation gene 3. Science, 353, aah3374.

Maroteaux, L., Campanelli, J.T. \& Scheller, R.H. (1988) Synuclein: a neuron-specific protein localized to the nucleus and presynaptic nerve terminal. J. Neurosci., 8, 2804-2815.

Masuda-Suzukake, M., Nonaka, T., Hosokawa, M., Oikawa, T., Arai, T., Akiyama, H., Mann, D.M. \& Hasegawa, M. (2013) Prion-like spreading of pathological alpha-synuclein in brain. Brain, 136, 1128-1138.

Matsuda, N. (2016) Phospho-ubiquitin: upending the PINKParkin-ubiquitin cascade. J. Biochem., 159, 379-385.

Matsuzaki, M., Hasegawa, T., Takeda, A., Kikuchi, A., Furukawa, K., Kato, Y. \& Itoyama, Y. (2004) Histochemical features of stress-induced aggregates in alpha-synuclein overexpressing cells. Brain Res., 1004, 83-90.

Mazzulli, J.R., Xu, Y.H., Sun, Y., Knight, A.L., McLean, P.J., Caldwell, G.A., Sidransky, E., Grabowski, G.A. \& Krainc, D. (2011) Gaucher disease glucocerebrosidase and alpha-synuclein form a bidirectional pathogenic loop in synucleinopathies. Cell, 146, 37-52.

McGough, I.J., Steinberg, F., Jia, D., Barbuti, P.A., McMillan, K.J., Heesom, K.J., Whone, A.L., Caldwell, M.A., Billadeau, D.D., Rosen, M.K. \& Cullen, P.J. (2014) Retromer binding to FAM2 1 and the WASH complex is perturbed by the Parkinson disease-linked VPS35(D620N) mutation. Curr. Biol., 24, 1670-1676.

Mercado, G., Castillo, V., Soto, P. \& Sidhu, A. (2016) ER stress and Parkinson's disease: Pathological inputs that converge into the secretory pathway. Brain Res., 1648, 626-632.

Miura, E., Hasegawa, T., Konno, M., Suzuki, M., Sugeno, N., Fujikake, N., Geisler, S., Tabuchi, M., Oshima, R., Kikuchi, A., Baba, T., Wada, K., Nagai, Y., Takeda, A. \& Aoki, M. (2014) VPS35 dysfunction impairs lysosomal degradation of alpha-synuclein and exacerbates neurotoxicity in a Drosophila model of Parkinson's disease. Neurobiol. Dis., 71, 1-13.

Mizuno, Y., Yoshino, H., Ikebe, S., Hattori, N., Kobayashi, T., Shimoda-Matsubayashi, S., Matsumine, H. \& Kondo, T. (1998) Mitochondrial dysfunction in Parkinson's disease. Ann. Neurol., 44, S99-109.

Muller, M.P. \& Goody, R.S. (2017) Molecular control of Rab activity by GEFs, GAPs and GDI. Small GTPases, 1-17, doi: 10.1080/21541248.2016.1276999. [Epub ahead of print].

Nakai, M., Fujita, M., Waragai, M., Sugama, S., Wei, J., Akatsu, H., Ohtaka-Maruyama, C., Okado, H. \& Hashimoto, M. (2007) Expression of alpha-synuclein, a presynaptic protein implicated in Parkinson's disease, in erythropoietic lineage. Biochem. Biophys. Res. Commun., 358, 104-110.

Odagiri, H., Baba, T., Nishio, Y., Iizuka, O., Matsuda, M., Inoue, K., Kikuchi, A., Hasegawa, T., Aoki, M., Takeda, A., Taki, Y. \& Mori, E. (2016) On the Utility of MIBG SPECT/CT in Evaluating Cardiac Sympathetic Dysfunction in Lewy Body Diseases. PLoS One, 11, e0152746.

Oshima, R., Hasegawa, T., Tamai, K., Sugeno, N., Yoshida, S., Kobayashi, J., Kikuchi, A., Baba, T., Futatsugi, A., Sato, I., Satoh, K., Takeda, A., Aoki, M. \& Tanaka, N. (2016) ESCRT-0 dysfunction compromises autophagic degradation of protein aggregates and facilitates ER stress-mediated neurodegeneration via apoptotic and necroptotic pathways. Sci. Rep., 6, 24997.

Outeiro, T.F. \& Lindquist, S. (2003) Yeast cells provide insight into alpha-synuclein biology and pathobiology. Science, 302, 1772-1775.

Pankratz, N., Wilk, J.B., Latourelle, J.C., DeStefano, A.L., Halter, C., Pugh, E.W., Doheny, K.F., Gusella, J.F., Nichols, W.C., Foroud, T. \& Myers, R.H. (2009) Genomewide association study for susceptibility genes contributing to familial Parkinson disease. Hum. Genet., 124, 593-605.

Parkinson, J. (1817) An Essay on the Shaking Palsy, Whittingham and Rowland for Sherwood, Neely, and Jones, London.

Perrin, R.J., Woods, W.S., Clayton, D.F. \& George, J.M. (2000) Interaction of human alpha-Synuclein and Parkinson's disease variants with phospholipids. Structural analysis using sitedirected mutagenesis. J. Biol. Chem., 275, 34393-34398.

Peters, P.J., Mironov, A. Jr., Peretz, D., van Donselaar, E., Leclerc, E., Erpel, S., DeArmond, S.J., Burton, D.R., Williamson, R.A., Vey, M. \& Prusiner, S.B. (2003) Trafficking of prion proteins through a caveolae-mediated endosomal pathway. J. Cell Biol., 162, 703-717.

Pfeffer, S.R. (2017) Rab GTPases: master regulators that establish the secretory and endocytic pathways. Mol. Biol. Cell, 28, $712-715$.

Polymeropoulos, M.H., Lavedan, C., Leroy, E., Ide, S.E., Dehejia, A., Dutra, A., Pike, B., Root, H., Rubenstein, J., Boyer, R., 
Stenroos, E.S., Chandrasekharappa, S., Athanassiadou, A., Papapetropoulos, T., Johnson, W.G., et al. (1997) Mutation in the alpha-synuclein gene identified in families with Parkinson's disease. Science, 276, 2045-2047.

Porto-Carreiro, I., Fevrier, B., Paquet, S., Vilette, D. \& Raposo, G. (2005) Prions and exosomes: from PrPc trafficking to PrPsc propagation. Blood Cells Mol. Dis., 35, 143-148.

Prusiner, S.B., Woerman, A.L., Mordes, D.A., Watts, J.C., Rampersaud, R., Berry, D.B., Patel, S., Oehler, A., Lowe, J.K., Kravitz, S.N., Geschwind, D.H., Glidden, D.V., Halliday, G.M., Middleton, L.T., Gentleman, S.M., Grinberg, L.T. \& Giles, K. (2015) Evidence for alpha-synuclein prions causing multiple system atrophy in humans with parkinsonism. Proc. Natl. Acad. Sci. USA, 112, E5308-5317.

Raiborg, C. \& Stenmark, H. (2009) The ESCRT machinery in endosomal sorting of ubiquitylated membrane proteins. Nature, 458, 445-452.

Rockenstein, E., Mallory, M., Hashimoto, M., Song, D., Shults, C.W., Lang, I. \& Masliah, E. (2002) Differential neuropathological alterations in transgenic mice expressing alpha-synuclein from the platelet-derived growth factor and Thy-1 promoters. J. Neurosci. Res., 68, 568-578.

Rodriguez, J.A., Piddini, E., Hasegawa, T., Miyagi, T. \& Dotti, C.G. (2001) Plasma membrane ganglioside sialidase regulates axonal growth and regeneration in hippocampal neurons in culture. J. Neurosci., 21, 8387-8395.

Roosen, D.A. \& Cookson, M.R. (2016) LRRK2 at the interface of autophagosomes, endosomes and lysosomes. Mol. Neurodegener., 11, 73.

Rothfuss, O., Fischer, H., Hasegawa, T., Maisel, M., Leitner, P., Miesel, F., Sharma, M., Bornemann, A., Berg, D., Gasser, T. \& Patenge, N. (2009) Parkin protects mitochondrial genome integrity and supports mitochondrial DNA repair. Hum. Mol. Genet., 18, 3832-3850.

Schapira, A.H. (2015) Glucocerebrosidase and Parkinson disease: Recent advances. Mol. Cell. Neurosci., 66, 37-42.

Schell, H., Hasegawa, T., Neumann, M. \& Kahle, P.J. (2009) Nuclear and neuritic distribution of serine-129 phosphorylated alpha-synuclein in transgenic mice. Neuroscience, 160, 796-804.

Seaman, M.N. (2004) Cargo-selective endosomal sorting for retrieval to the Golgi requires retromer. J. Cell Biol., 165, 111-122.

Seaman, M.N.J. \& Freeman, C.L. (2014) Analysis of the Retromer complex-WASH complex interaction illuminates new avenues to explore in Parkinson disease. Commun. Integr. Biol., 7, e29483.

Soper, J.H., Kehm, V., Burd, C.G., Bankaitis, V.A. \& Lee, V.M. (2011) Aggregation of alpha-synuclein in S. cerevisiae is associated with defects in endosomal trafficking and phospholipid biosynthesis. J. Mol. Neurosci., 43, 391-405.

Soria, F.N., Pampliega, O., Bourdenx, M., Meissner, W.G., Bezard, E. \& Dehay, B. (2017) Exosomes, an Unmasked Culprit in Neurodegenerative Diseases. Front. Neurosci., 11, 26.

Spillantini, M.G., Schmidt, M.L., Lee, V.M., Trojanowski, J.Q., Jakes, R. \& Goedert, M. (1997) Alpha-synuclein in Lewy bodies. Nature, $\mathbf{3 8 8}, 839-840$.

Stefanova, N., Seppi, K., Scherfler, C., Puschban, Z. \& Wenning, G.K. (2000) Depression in alpha-synucleinopathies: prevalence, pathophysiology and treatment. J. Neural. Transm. Suppl., 8, 335-343.

Sudhof, T.C. \& Rizo, J. (2011) Synaptic vesicle exocytosis. Cold Spring Harb Perspect. Biol., 3, a005637.

Sugeno, N., Hasegawa, T., Tanaka, N., Fukuda, M., Wakabayashi, K., Oshima, R., Konno, M., Miura, E., Kikuchi, A., Baba, T., Anan, T., Nakao, M., Geisler, S., Aoki, M. \& Takeda, A. (2014) Lys-63-linked ubiquitination by E3 ubiquitin ligase Nedd4-1 facilitates endosomal sequestration of internalized alpha-synuclein. J. Biol. Chem., 289, 18137-18151.
Sugeno, N., Jackel, S., Voigt, A., Wassouf, Z., Schulze-Hentrich, J. \& Kahle, P.J. (2016) alpha-Synuclein enhances histone H3 lysine-9 dimethylation and H3K9me2-dependent transcriptional responses. Sci. Rep., 6, 36328.

Sugeno, N., Takeda, A., Hasegawa, T., Kobayashi, M., Kikuchi, A., Mori, F., Wakabayashi, K. \& Itoyama, Y. (2008) Serine 129 phosphorylation of alpha-synuclein induces unfolded protein response-mediated cell death. J. Biol. Chem., 283, 2317923188.

Sung, J.Y., Kim, J., Paik, S.R., Park, J.H., Ahn, Y.S. \& Chung, K.C. (2001) Induction of neuronal cell death by Rab5A-dependent endocytosis of alpha-synuclein. J. Biol. Chem., 276, 2744127448.

Takeda, A., Baba, T., Kikuchi, A., Hasegawa, T., Sugeno, N., Konno, M., Miura, E. \& Mori, E. (2014) Olfactory dysfunction and dementia in Parkinson's disease. J. Parkinsons Dis., 4, 181-187.

Takeda, A., Hasegawa, T., Matsuzaki-Kobayashi, M., Sugeno, N., Kikuchi, A., Itoyama, Y. \& Furukawa, K. (2006) Mechanisms of neuronal death in synucleinopathy. J. Biomed. Biotechnol., 2006, 19365

Takeda, A., Saito, N., Baba, T., Kikuchi, A., Sugeno, N., Kobayashi, M., Hasegawa, T. \& Itoyama, Y. (2010) Functional imaging studies of hyposmia in Parkinson's disease. $J$. Neurol. Sci., 289, 36-39.

Tanner, C.M., Kamel, F., Ross, G.W., Hoppin, J.A., Goldman, S.M., Korell, M., Marras, C., Bhudhikanok, G.S., Kasten, M., Chade, A.R., Comyns, K., Richards, M.B., Meng, C., Priestley, B., Fernandez, H.H., Cambi, F., Umbach, D.M., Blair, A., Sandler, D.P. \& Langston, J.W. (2011) Rotenone, Paraquat, and Parkinson's Disease. Environ. Health Perspect., 119, 866-872.

Tsunemi, T., Hamada, K. \& Krainc, D. (2014) ATP13A2/PARK9 regulates secretion of exosomes and alpha-synuclein. $J$. Neurosci., 34, 15281-15287.

Ueda, K., Saitoh, T. \& Mori, H. (1994) Tissue-dependent alternative splicing of mRNA for NACP, the precursor of non-A beta component of Alzheimer's disease amyloid. Biochem. Biophys. Res. Commun., 205, 1366-1372.

Vella, L.J., Greenwood, D.L., Cappai, R., Scheerlinck, J.P. \& Hill, A.F. (2008) Enrichment of prion protein in exosomes derived from ovine cerebral spinal fluid. Vet. Immunol. Immunopathol., 124, 385-393.

Vilarino-Guell, C., Rajput, A., Milnerwood, A.J., Shah, B., Szu-Tu, C., Trinh, J., Yu, I., Encarnacion, M., Munsie, L.N., Tapia, L., Gustavsson, E.K., Chou, P., Tatarnikov, I., Evans, D.M., Pishotta, F.T., et al. (2014) DNAJC13 mutations in Parkinson disease. Hum. Mol. Genet., 23, 1794-1801.

Vilarino-Guell, C., Wider, C., Ross, O.A., Dachsel, J.C., Kachergus, J.M., Lincoln, S.J., Soto-Ortolaza, A.I., Cobb, S.A., Wilhoite, G.J., Bacon, J.A., Behrouz, B., Melrose, H.L., Hentati, E., Puschmann, A., Evans, D.M., et al. (2011) VPS35 Mutations in Parkinson Disease. Am. J. Hum. Genet., 89, 162-167.

Vilchez, D., Saez, I. \& Dillin, A. (2014) The role of protein clearance mechanisms in organismal ageing and age-related diseases. Nat. Commun., 5, 5659.

Volles, M.J. \& Lansbury, P.T. Jr. (2002) Vesicle permeabilization by protofibrillar alpha-synuclein is sensitive to Parkinson's disease-linked mutations and occurs by a pore-like mechanism. Biochemistry, 41, 4595-4602.

Volpicelli-Daley, L.A., Gamble, K.L., Schultheiss, C.E., Riddle, D.M., West, A.B. \& Lee, V.M. (2014) Formation of alphasynuclein Lewy neurite-like aggregates in axons impedes the transport of distinct endosomes. Mol. Biol. Cell, 25, 40104023.

Wakabayashi, K., Tanji, K., Mori, F. \& Takahashi, H. (2007) The Lewy body in Parkinson's disease: molecules implicated in the formation and degradation of alpha-synuclein aggregates. 
Neuropathology, 27, 494-506.

Walker, L.C. \& Jucker, M. (2015) Neurodegenerative diseases: expanding the prion concept. Ann. Rev. Neurosci., 38, 87-103.

Wang, D., Chan, C.C., Cherry, S. \& Hiesinger, P.R. (2013) Membrane trafficking in neuronal maintenance and degeneration. Cell. Mol. Life Sci., 70, 2919-2934.

Waschbusch, D., Michels, H., Strassheim, S., Ossendorf, E., Kessler, D., Gloeckner, C.J. \& Barnekow, A. (2014) LRRK2 transport is regulated by its novel interacting partner Rab32. PLoS One, 9, e111632.

Weinreb, P.H., Zhen, W., Poon, A.W., Conway, K.A. \& Lansbury, P.T. Jr. (1996) NACP, a protein implicated in Alzheimer's disease and learning, is natively unfolded. Biochemistry, 35, 13709-13715.

Westphal, C.H. \& Chandra, S.S. (2013) Monomeric synucleins generate membrane curvature. J. Biol. Chem., 288, 18291840 .

Wickner, W. \& Rizo, J. (2017) A cascade of multiple proteins and lipids catalyzes membrane fusion. Mol. Biol. Cell, 28, 707-711.

Wilson, G.R., Sim, J.C., McLean, C., Giannandrea, M., Galea,
C.A., Riseley, J.R., Stephenson, S.E., Fitzpatrick, E., Haas, S.A., Pope, K., Hogan, K.J., Gregg, R.G., Bromhead, C.J., Wargowski, D.S., Lawrence, C.H., et al. (2014) Mutations in RAB39B cause X-linked intellectual disability and early-onset Parkinson disease with alpha-synuclein pathology. Am. J. Hum. Genet., 95, 729-735.

Zavodszky, E., Seaman, M.N., Moreau, K., Jimenez-Sanchez, M., Breusegem, S.Y., Harbour, M.E. \& Rubinsztein, D.C. (2014) Mutation in VPS35 associated with Parkinson's disease impairs WASH complex association and inhibits autophagy. Nat. Commun., 5, 3828.

Zhang, Y., Grant, B. \& Hirsh, D. (2001) RME-8, a conserved $\mathrm{J}$-domain protein, is required for endocytosis in Caenorhabditis elegans. Mol. Biol. Cell, 12, 2011-2021.

Zimprich, A., Benet-Pages, A., Struhal, W., Graf, E., Eck, S.H., Offman, M.N., Haubenberger, D., Spielberger, S., Schulte, E.C., Lichtner, P., Rossle, S.C., Klopp, N., Wolf, E., Seppi, K., Pirker, W., et al. (2011) A Mutation in VPS35, Encoding a Subunit of the Retromer Complex, Causes Late-Onset Parkinson Disease. Am. J. Hum. Genet., 89, 168-175. 